\title{
Vesicouterine Fistula Following Vaginal Birth after Caesarean Section in a Multiparous Woman- A Rare Case Report and Review of Literature
}

\author{
Dr Lajya Devi Goyal \\ MD MNAMS, Professor, Deptt. Of Obstetrics \& Gynecology, Guru Gobind Singh Medical College \& \\ Hospital, Baba Farid University of Health Sciences, Faridkot
}

Keywords: Vesicouterine Fistula, VBAC; vaginal birth after caesarean section.

\section{INTRODUCTION}

Vesicouterine fistulas (VUF) are rare and account for 1- 5\% of all urogenital fistulas[1]. Cesarean delivery accounts for $88 \%$ cases of vesico uterine fistula [2]. Vesicouterine fistula following vaginal birth after ceserean section is rarer still. There are very few cases of such spontaneous fistulas reported so far. Present case is rare case of vesicouterine fistula in multiparous lady occurring after vaginal birth after caesarean section (VBAC) on fourth postpartum day. Diagnosis was confirmed by cystoscopy. Successful uterine-conserving repair of the fistula was obtained via laparotomy with fistula closure and an omental flap approach.

\section{CASe Report}

A 36 year old multiparous lady presented in outpatient clinic of our hospital with complaints of lower abdominal pain and incontinence of urine since last 5 years. She had first normal full term vaginal delivery and her second delivery was by Caesarean section for breech 8 years back. Her last full term VBAC was home conducted five years back. There was no history of prolonged labour or difficult delivery. There was no significant past medical or surgical history. Her menstrual cycles were regular with scanty flow. However she noticed dribbling of urine from the $4^{\text {th }}$ postpartum day. On per speculum examination cervix was torn anteriorly extending up to fornix and urine was seen dribbling through the cervix. Diagnosis was confirmed by cystoscopy which revealed about two centimetre fistulous opening on posterior bladder wall above the trigon near the left ureteric orifice.

Patient was worked up for surgery and planned for abdominal route of repair. Intravenous antibiotic were started. Intraoperatively there were adhesions between bladder and uterus. An elliptical fistula was present in the isthmic region between the bladder and the uterus. Intravesical repair approach was chosen. Bladder was opened and fistula was identified. Bilateral ureteric orifices were cannulated, fistulous tract excised and defect was repaired in layers. Uterine defect was repaired separately. An omental flap was interposed between posterior bladder wall and uterus. Indwelling urethral and suprapubic catheter were left in situ. Retropubic drain was placed and bilateral tubal ligation was done. Postoperatively urine output and patency of both catheters was monitored. Perurethral catheter was removed on day fourteen and suprapubic catheter on day seven. Patient was discharged satisfactorily in a continent condition. Follow up visit after two months she was continent.

\section{DisCUSSION}

Vesicouterine fistulas are rare and account for 1- 5\% of all urogenital fistulas [1]. Majority of vesicouterine fistulas result from lower segment Caesarean section although other diverse aetiologies like induced abortion, ruptured uterus and supracervical hysterectomy, radium insertion, vaginal gynaecologic procedure have been documented in literature [2.3]

There are very few case reports of fistula occurring spontaneously during normal vaginal birth after Caesarean section to the best of our knowledge [5.6.7].

Clinical presentation depends on level of fistulous communication between the urinary bladder and uterus[1]. Patient may present with the symptoms of urinary incontinence if fistula is at or below the 


\section{Lajya Devi Goyal}

level of isthmus as in our patient or may present with the classical symptoms of amenorrhoea, cyclical menouria and incontinence of urine termed as Youssef syndrome if fistula is above the level of isthmus as seen in $30 \%$ of the presentations.

Józwik and Józwik have proposed a classification for uterovesical fistula which is based on the route of menstrual flow. Type 1 (Youssef syndrome) is menouria, amenorrhoea, and complete continence of urine. Type 2 is dual direction menstrual flow via bladder and vagina. Type 3 is normal vaginal menses but lack of menouria. Our patient had type 3 uterovesical fistula according to this classification [8].

Confirmation of diagnosis can be done by cystogram or hysterogram for outlining the fistulous tract by endoscopic visualisation of fistula orifice in the bladder or MRI $[9,10]$.

The operation can be transperitoneal or retroperitoneal either by laparotomy or by laparoscpy [11]. Surgery of choice depends on patient's desire for conservation of reproductive potential. Total abdominal hysterectomy and repair of fistulous tract is done in patient's nearing menopause or when associated uterine pathology is present. A transvesical approach involving fulguration of vesical opening has also been described but with a high recurrence rate [7].

Although our patient had completed her family she wanted to conserve her uterus, hence transabdominal approach was used to disconnect the fistula; excision of fistulous tract and scar tissue was done followed by meticulous multilayered closure. The pregnancy rate after repair has been reported to be $31.25-37.5 \%$ with a rate of term deliveries of $25 \%{ }^{1}$.

Fistulae can be prevented by meticulous practice of surgical principles at caesarean section, caudal retraction of the bladder, and identification of the anatomical landmarks with suturing, thorough investigation of intraoperative suspected injury of urogenital tract.

\section{Conclusion}

The issue of rising number of caesarean sections needs to be addressed to since it is responsible for the increase in number of morbid conditions like uterovesical fistulas. Vaginal birth after caesarean should be attempted after weighing pros and cons of these morbid conditions.

\section{REFERENCES}

[1] Kilinc F, Bagis T. Unusual case of post-cesarean vesicouterine fistula (Youssef's syndrome). International Journal of Urology. 2003;10(4):235-8.

[2] Ikechebelu JI, Ugboaja JO, Okeke CF Post-cesarean vesicouterine fistula (Youssef syndrome): report of two cases. J Obstet Gynaecol Res:2011: 37: 912-915

[3] Bhatt S, Thomas A. Youssef Syndrome-Report of 7 Cases and Review of Literature.JIMA Feb $2004 ; 102(2): 86-8$

[4] Karaltı MO, Tinar Ş, Öztürk NT, Öztekin DC. A case with vesicouterine fistula: mini review. Arch Gynecol Obstet. 2012;285:667-70.

[5] Holden D, Vere M, Manyonda I. Vesicouterine fistula occurring in a woman with a previous Caesarean section and two subsequent normal vaginal deliveries. Br J Obstet Gynecol 1994; 101: 354-6

[6] Miklos J, Sze E. Vesicouterine fistula- a rare complication of vaginal birth after Caesarean. Obstet Gynecol 1995; 86: 638-9

[7] Kaaki B, Gyves M .Spontaneous Intrapartum Vesicouterine fistula. .Obstet Gynecol 2006 :44950.

[8] Józwik M, Józwik M. Clinical classification of vesicouterine fistula. Int J Gynaecol Obstet. 2000;70(3):353-7

[9] Goel A, Goel S, Singh BP, Sankhwar SN. Cystographic images of Youssef syndrome: flower on top of the bladder. Urology. 2012;79:e69-70.

[10] Abou-El-Ghar ME, El-Assmy AM, Refai HF, El-Diasty TA. Radiological diagnosis of vesicouterine fistula: role of magnetic resonance imaging. J Magn Reson Imaging. 2012;36:43842.

[11] Garza Cortés R, Clavijo R, Sotelo R. Laparoscopic treatment of genitourinary fistulae. Arch Esp Urol. 2012;65:659-72 